term basis to medical inpatients. Since there is no pharmacological evidence to support the current practice of using two different benzodiazepines together, and a potential reduction in cost to the Health Service of changing the practice, we undertook a randomised double-blind patient-preference study to test the hypothesis that one of the three commonly used benzodiazepines (flurazepam, nitrazepam, and diazepam) was better than the others as a short-term hypnotic in medical inpatients.

This study design was chosen because of simplicity, economy in staff time, minimum patient interference, use of each patient as his own control, and the benefits of a sequential analysis design. Such trial methods have been shown to be reproducible and reliable in assessing symptomatic drug treatment qualitatively provided only that the basic symptoms under treatment do not vary on a daily basis. ${ }^{3}$ Variability of symptoms in patientpreference studies are of considerable significance and may invalidate the use of this technique. ${ }^{7}$ Nevertheless, this did not constitute a significant problem in our study, and Zelvelder, ${ }^{8}$ in an extensive review of the techniques of evaluating hypnotics, recommended this approach as the most efficient one available for evaluating short-term hypnotic efficacy. Our studies confirmed that the benzodiazepines are effective hypnotics ${ }^{9}$ and failed to show a clinically significant difference in efficacy between them when used in this setting. Despite the relatively small numbers of patients, the incidence of undesired effects (usually excessive sedation) seemed to be higher with nitrazepam than with diazepam or flurazepam. Our data also show that older patients admitted to medical wards have a significant preference for a benzodiazepine as a hypnotic rather than an antihistamine.

This work was supported by a generous grant from the Scottish Home and Health Department and by Roche Products Ltd. Data from the pharmacy department, Glasgow Royal Infirmary, were kindly provided by Miss J Fleming.

Requests for reprints should be addressed to $\mathrm{Dr} C \mathrm{M}$ Kesson.

\section{References}

1 Greenblatt, D J, and Shader, R I, Benzodiazepines in Clinical Practice. New York, Raven Press, 1974

2 Barraclough, B M, Lancet, 1974, 1, 57

3 Thomson, T J, British Medical fournal, 1958, 2, 1140.

${ }^{4} \mathrm{Jick}, \mathrm{H}$, et al, New England fournal of Medicine, 1966, 275, 1399.

5 Snell, E S, and Armitage, P, Lancet, 1957, 1, 860.

6 Parsons, T W, and Thomson, T J, British Medical fournal, 1961, 1, 171

Huskisson, E C, and Grayson, M F, British fournal of Clinical Pharmacology, 1974, 1, 151.

${ }^{8}$ Zelvelder, W G, Therapeutic Evaluation of Hypnotics. London, Heinemann, 1971.

9 Kales, A, and Scharf, M B, The Benzodiazepines. New York, Raven Press, 1973.

\title{
Spironolactone in essential hypertension: evidence against its effect through mineralocorticoid antagonism
}

\author{
B I HOFFBRAND, C J EDMONDS, T SMITH
}

British Medical fournal, 1976, 1, 682-684

\begin{abstract}
Summary
The effect of a six-week course of spironolactone $300 \mathrm{mg} /$ day was examined in 25 unselected patients with essential hypertension. In the blood spironolactone produced a significant rise in urea and potassium concentrations and a fall in sodium and bicarbonate concentrations. In six patients blood pressure was normal at the end of the course, while in five patients there was almost no change. Studies of the effects of spironolactone on various indices usually affected by mineralocorticoids-namely, blood electrolytes, total body potassium, and rectal electrical properties-showed no differences between responding and non-responding patients. Mineralocorticoid excess therefore seems to be rarely responsible for essential hypertension and the influence of spironolactone cannot at present be fully explained.
\end{abstract}

\section{Introduction}

Spironolactone has been known for many years to have hypotensive properties. In primary hyperaldosteronism it rapidly

Whittington Hospital, Archway Road, London N19 5NF

B I HOFFBRAND, MD, MRCP, consultant physician

Clinical Research Centre, Harrow, Middlesex HA1 3UJ

C J EDMONDS, MD, FRCP, consultant physician and member of MRC scientific staff

T SMITH, BSC, PHD, physicist and member of MRC scientific staff corrects the biochemical abnormalities and usually restores the blood pressure to normal. ${ }^{1}$ In essential hypertension spironolactone in a daily dose of about $100 \mathrm{mg}$ has a hypotensive effect about the same as that of the thiazide diuretics. ${ }^{3}$ Several workers have shown that in essential hypertension spironolactone is especially effective among patients with subnormal blood renin levels (low renin hypertension), ${ }^{4-6}$ which suggests that low renin hypertension may be due to increased mineralocorticoid activity. Conversely, it has been argued that patients with essential hypertension who respond to spironolactone are likely to have mineralocarticoid excess. ${ }^{7}$ Such mineralocorticoid excess has, however, only rarely been shown in hypertensive patients. An alternative suggestion ${ }^{8}$ is that aldosterone itself is responsible since although the blood levels are within the normal range they may, nevertheless, be inappropriately high for the blood renin concentrations. Our object was to investigate a group of untreated patients with essential hypertension to examine the effect of spironolactone on blood pressure and some biological indices of mineralocorticoid activity to determine whether there was any difference between those patients whose blood pressure responded to spironolactone and those whose blood pressure did not respond. The transepithelial electrical potential difference of rectal mucosa rises considerably when stimulated by aldosterone and other mineralocorticoids, ${ }^{9-13}$ reflecting the increase of sodium transport, and we used this as one of the indices of mineralocorticoid activity.

\section{Methods}

Studies were done on 25 untreated outpatients ( 14 men, 11 women) whose supine diastolic blood pressures were over $100 \mathrm{~mm} \mathrm{Hg}$ on at least three occasions. A preliminary observation period of at least four weeks preceded the administration of spironolactone. The mean age 
was 42 years (range 26-55 years). The diagnosis of essential hypertension was established by initial investigations, and none of the patients had any abnormality of renal function or serum electrolytes. The patients had no detectable complications of hypertension and were in good general health.

Blood pressure was measured by standard mercury sphygmomanometry after three minutes supine and after one minute erect. Blood biochemistry was done by routine laboratory techniques. Total body potassium was measured by determing the ${ }^{40} \mathrm{~K}$ content of each patient using a liquid scintillation whole-body counter as described. ${ }^{14} 15$ The errors of the method result in a coefficient of variation of $4.2 \%$ for measurement of a person with a total body potassium of $3500 \mathrm{mmol}(3500 \mathrm{mEq})$. For each patient an expected value for total body potassium was obtained based on age, sex, height, and weight using relations determined in a study of a normal population. ${ }^{16}$ The potential difference of the rectal mucosa was measured as described by Archampong and Edmonds. ${ }^{17}$ The probe electrode was inserted through a proctoscope under direct vision and 15 replicate measurements made over the region of the bowel $8-10 \mathrm{~cm}$ from the anus. The mean of the results was recorded.

The standard protocol consisted of an initial measurement of blood pressure, blood biochemistry, rectal potential difference, and total body potassium. The responsiveness of the rectal mucosa to mineralocorticoids was then tested by giving two doses of 9 - $\alpha$-fluorocortisol $0.5 \mathrm{mg}$ at 24 and 12 hours before a further rectal potential difference measurement. Spironolactone (Aldactone-A) $100 \mathrm{mg}$ three times a day was then prescribed and a full set of measurements (blood pressure, blood biochemistry, total body potassium, and rectal potential difference) repeated after six weeks of spironolactone administration. Body weight was recorded under standard conditions on each occasion. All patients gave their informed consent.

\section{Results}

The patients fell into three groups on the basis of the blood pressure level reached at the end of six weeks' treatment with spironolactone (table I). Six patients (three men, three women) responded to treatment; their diastolic blood pressures fell to less than $90 \mathrm{~mm} \mathrm{Hg}$. Five non-responsive patients (two men, three women) showed no significant change in diastolic blood pressure and little change in systolic pressure. The blood pressures of the remaining patients (nine men, five women) altered in varying degrees.

When all the patients were considered together spironolactone produced a small significant fall in mean weight ( $\pm S E$ of mean) of $1.9 \pm 0.5 \mathrm{~kg}(\mathrm{P}<0.001)$. There were, however, no significant differences in weight loss between the groups (table I). Statistically significant changes in blood biochemistry were produced by spironolactone, with an increase in serum urea $(P<0.001)$ and potassium $(P<0.001)$ concentrations and a reduction of sodium $(P=0.001)$ and bicarbonate $(\mathrm{P}<0.005)$ concentrations. The mean initial total body potassium values in all groups were not significantly different from each other or from predicted values (table II). Moreover, no significant changes in total body potassium were observed after spironolactone in any of the patients, all groups sharing essentially similar results.

The initial mean rectal potential difference values ( \pm SE of mean) of the hypertensive patients were normal $(40 \pm 3 \mathrm{mV})$, as established by measurements on normal adults. ${ }^{17}$ There was also no significant difference between the values of the responsive patients and those of the non-responsive patients. Exogenous mineralocorticoid stimulation by $9-\alpha$-fluorocortisol produced a rise of potential difference in all groups similar to that found in normal people, and spironolactone produced a fall. In these respects too the three groups appeared to behave similarly.

The change in erect mean blood pressure associated with spironolactone administration was compared with various other changes to investigate possible correlations. No significant correlation was found between the blood pressure change and changes in weight, total body potassium, serum potassium concentration, or rectal potential difference. The initial rectal potential difference also showed no significant correlation with the subsequent blood pressure change.

\section{Discussion}

Low renin hypertension appears to be relatively common, occurring in about $20-30 \%$ of patients with essential hypertension. ${ }^{1819}$ Some have questioned the significance of the finding of low renin and poorly responsive renin levels and suggested that low renin hypertension is not a clinical entity. ${ }^{20} 21$ Clearly, however, if low renin hypertension were due to excessive production of mineralocorticoid hormones then mineralocorticoid-induced hypertension would be common despite the rarity of primary aldosteronism itself. Spironolactone in adequate doses would therefore be expected to reduce the raised blood pressure to normal in many patients. In our study this did appear to be so, for in about a quarter of the patients the blood pressure was normal at the end of the course.

There was nothing in our other observations, however, to suggest that these responding patients had excessive mineralocorticoid activity. The small reduction in weight, presumably indicating a small reduction of total body fluid, was similar in all groups, as were the changes in serum sodium, potassium, and bicarbonate concentrations. There was no evidence of depleted body potassium in the responding group, as shown by either the

TABLE I-Comparison of mean blood pressure, body weight, and blood chemistry ( $\pm S E$ of mean) between groups

\begin{tabular}{|c|c|c|c|c|c|c|c|c|c|c|}
\hline & & & \multicolumn{2}{|c|}{$\begin{array}{l}\text { Supine blood pressure } \\
(\mathrm{mm} \mathrm{Hg})\end{array}$} & \multicolumn{2}{|c|}{$\underset{(\mathrm{kg})}{\text { Weight }}$} & \multicolumn{4}{|c|}{$\begin{array}{l}\text { Blood chemistry } \\
(\mathrm{mmol} / \mathrm{l})\end{array}$} \\
\hline & & & Diastolic & Systolic & Initial & Weight change & Urea & $\mathrm{Na}$ & $\mathbf{K}$ & $\mathrm{HCO}_{3}$ \\
\hline \multicolumn{11}{|c|}{ Patients who responded } \\
\hline $\begin{array}{l}\text { Before spironolactone } \\
\text { After spironolactone. }\end{array}$ & $\begin{array}{l}\ldots \\
\cdots\end{array}$ & 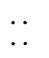 & $\begin{array}{r}107 \pm 3 \\
82 \pm 3\end{array}$ & $\begin{array}{l}169 \pm 4 \\
.126 \pm 14\end{array}$ & $71 \cdot 9 \pm 6$ & $-1 \cdot 1 \pm 0.5$ & $\begin{array}{l}4 \cdot 1 \pm 0 \cdot 5 \\
4 \cdot 8 \pm 0 \cdot 7\end{array}$ & $\begin{array}{l}140 \pm 1 \\
140 \pm 1\end{array}$ & $\begin{array}{l}3 \cdot 6 \pm 0 \cdot 1 \\
4 \cdot 1 \pm 0 \cdot 2\end{array}$ & $\begin{array}{l}24 \pm 1 \\
23 \pm 1\end{array}$ \\
\hline \multicolumn{11}{|c|}{ Patients who did not respond } \\
\hline $\begin{array}{l}\text { Before spironolactone } \\
\text { After spironolactone.. }\end{array}$ & 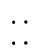 & $\begin{array}{l}\cdots \\
\cdots\end{array}$ & $\begin{array}{l}117 \pm 5 \\
116 \pm 5\end{array}$ & $\begin{array}{l}206 \pm 10 \\
175 \pm 10\end{array}$ & $71 \cdot 3 \pm 4$ & $-1.5 \pm 0.9$ & $\begin{array}{l}4 \cdot 8 \pm 0.5 \\
6 \cdot 8 \pm 0.7\end{array}$ & $\begin{array}{l}140 \pm 1 \\
138 \pm 1\end{array}$ & $\begin{array}{l}3 \cdot 8 \pm 0 \cdot 2 \\
4 \cdot 6 \pm 0 \cdot 3\end{array}$ & $\begin{array}{l}26 \pm 1 \\
25 \pm 2\end{array}$ \\
\hline \multicolumn{11}{|c|}{ Patients who responded partially } \\
\hline $\begin{array}{l}\text { Before spironolactone } \\
\text { After spironolactone. }\end{array}$ & $\ldots$ & $\because$ & $\begin{array}{r}114 \pm 2 \\
97 \pm 2\end{array}$ & $\begin{array}{l}183 \pm 6 \\
145 \pm 5\end{array}$ & $71 \cdot 1 \pm 2 \cdot 7$ & $-2 \cdot 3 \pm 0 \cdot 8$ & $\begin{array}{l}5 \cdot 0 \pm 0 \cdot 3 \\
7 \cdot 2 \pm 0 \cdot 5\end{array}$ & $\begin{array}{l}139 \pm 1 \\
137 \pm 1\end{array}$ & $\begin{array}{l}3 \cdot 8 \pm 0 \cdot 1 \\
4 \cdot 3 \pm 0 \cdot 1\end{array}$ & $\begin{array}{l}25 \pm 1 \\
21 \pm 1\end{array}$ \\
\hline
\end{tabular}

Conversion: SI to traditional units-Urea: $1 \mathrm{mmol} / 1 \approx 6 \mathrm{mg} / 100 \mathrm{ml}$. Na, $\mathrm{K}$, and $\mathrm{HCO}_{3}: 1 \mathrm{mmol} / 1=1 \mathrm{mEq} / \mathrm{l}$.

TABLE II-Comparison of mean total body potassium and rectal electrical potential difference ( $\pm S E$ of mean) between groups

\begin{tabular}{|c|c|c|c|c|c|c|c|c|}
\hline & & \multicolumn{4}{|c|}{ Total body potassium } & \multicolumn{3}{|c|}{ Rectal potential difference (mV) } \\
\hline & & \multirow{2}{*}{$\underset{(\mathrm{mmol})}{\text { Expected }}$} & \multicolumn{2}{|c|}{ Observed } & \multirow{2}{*}{$\begin{array}{l}\text { After } \\
\text { spironolactone } \\
(\mathrm{mmol})\end{array}$} & \multirow{2}{*}{ Initial } & \multirow{2}{*}{$\begin{array}{l}\text { After } \\
\text { 9- } \alpha \text {-fluoro- } \\
\text { cortisol }\end{array}$} & \multirow{2}{*}{$\begin{array}{l}\text { After } \\
\text { spironolactone }\end{array}$} \\
\hline & & & $(\mathrm{mmol})$ & $(\mathrm{mmol} / \mathrm{kg})$ & & & & \\
\hline $\begin{array}{l}\text { Patients who responded } \\
\text { Patients who did not respond } \\
\text { Patients who responded partially }\end{array}$ & $\begin{array}{l}\cdots \\
\cdots\end{array}$ & $\begin{array}{l}2837 \pm 276 \\
2861 \pm 365 \\
2978 \pm 137\end{array}$ & $\begin{array}{l}3103 \pm 430 \\
2943 \pm 772 \\
3129 \pm 188\end{array}$ & $\begin{array}{l}44 \pm 3 \\
41 \pm 6 \\
44 \pm 2\end{array}$ & $\begin{array}{l}3130 \pm 442 \\
2956 \pm 748 \\
3126 \pm 165\end{array}$ & $\begin{array}{l}36 \pm 3 \\
34 \pm 3 \\
33 \pm 2\end{array}$ & $\begin{array}{l}58 \pm 5 \\
61 \pm 3 \\
52 \pm 2\end{array}$ & $\begin{array}{l}24 \pm 2 \\
28 \pm 1 \\
27 \pm 1\end{array}$ \\
\hline
\end{tabular}


initial values or the lack of any significant change when spironolactone was given. Measurements of rectal potential difference also failed to show any difference between the groups. Thus the sodium transport system of the colon seemed to be unstimulated in the patients responding to spironolactone, to react normally to an exogenous mineralocorticoid stimulus (9- $\alpha$-fluorocortisol), and to reduce normally when spironolactone was given.

There are several possible explanations for our failure to find any evidence of biological effects of mineralocorticoidism in the responding group. Firstly, their hypertension may not have been due to mineralocorticoid excess, the action of spironolactone being through a mechanism other than mineralocorticoid antagonism. Secondly, the mineralocorticoids being produced may have lacked actions on sodium and potassium metabolism that we customarily expect. Thirdly, as suggested by Grim, ${ }^{8}$ although the serum aldosterone levels were in the normal range, they were possibly inappropriately high for the renin levels. Both of these latter suggestions are speculative and the most likely explanation is that mineralocorticoids are rarely responsible for the increase in blood pressure in patients with essential hypertension.

Our results do not, unfortunately, cast any certain light on the mode of action of spironolactone in essential hypertension since all the changes that we observed were common to all groups and occurred to similar degrees. The reduction of body fluid and body sodium may be the significant factor but, if so, these changes appear to lower blood pressure only in some patients.

We gratefully acknowledge the expert technical help given by Miss
Jennifer Mackenzie and to G D Searle and Co Ltd, for generously supplying spironolactone.

\section{References}

1 Brown, J J, et al, British Medical fournal, 1972, 1, 729.

2 Winer, B M, Lubbe, W F, and Colton, T, fournal of the American Medical Association, 1968, 204, 117.

3 Wolf, R I, et al, fournal of the American Medical Association, 1966, 198, 1143.

4 Adlin, E V, Biddle, C M, and Channick, B J, American fournal of Medical Science, 1971, 261, 67 .

5 Carey, R M, et al, Archives of Internal Medicine, 1972, 130, 849.

6 Spark, R F, and Melby, J C, Annals of Internal Medicine, 1971, 75, 831. Liddle, G W, Carey, R M, and Douglas, J G, Southern Medical fournal, 1973, 66, 51.

${ }^{8}$ Grim, E, Archives of Internal Medicine, 1975, 135, 347.

${ }^{9}$ Edmonds, C J, and Godfrey, R C, Gut, 1970, 11, 330.

${ }_{10}$ Edmonds, C J, and Richards, P, Lancet, 1970, 2, 624.

11 Beevers, D G, et al, Gut, 1975, 16, 36.

12 Efstratopoulos, A D, Peart, W S, and Wilson, G A, Clinical Science and Molecular Medicine, 1974, 46, 489.

13 Tomkins, A M, and Edmonds, C J, Gut, 1975, 16, 277.

14 Barnaby, C F, and Jasani, B M, Physics in Medicine and Biology, 1968, 13, 561.

15 Jasani, B M, and Edmonds, C J, Metabolism, 1971, 20, 1099.

16 Edmonds, C J, Jasani, B M, and Smith, T, Clinical Science and Molecular Medicine, 1975, 48, 431.

17 Archampong, E Q, and Edmonds, C J, Gut, 1972, 13, 559.

18 Crane, M G, Harris, J J, and Johns, V J, American fournal of Medicine, 1972, 52, 457.

19 Dunn, M J, and Tannen, R L, Kidney International, 1974, 5, 317.

${ }^{20}$ Lebel, M, et al, Lancet, 1974, 2, 308.

21 Padfield, P L, et al, Lancet, 1975, 1, 548.

\title{
Comparative double-blind study of cephalexin and co-trimoxazole in urinary tract infections
}

\author{
P E GOWER, P R W TASKER
}

British Medical fournal, 1976, 1, 684-686

\section{Summary}

Treatment with cephalexin $1 \mathrm{~g}$ twice daily and cotrimoxazole 2 tablets twice daily was compared in a double-blind, randomised study of 100 women with urinary tract infections. Co-trimoxazole gave a significantly higher cure rate compared with cephalexin two and six weeks after the one-week course of treatment. The higher failure rate with cephalexin was not related to the age of the patient, presentation, pyelographic appearances, or type of organism in the initial infection. Among the failures all but one of the organisms were sensitive to cephalexin. With the dosage regimen and duration of treatment used in this study cotrimoxazole appears to be superior to cephalexin in the management of acute urinary infections.

\section{Introduction}

Both cephalexin and co-trimoxazole have been used successfully to treat urinary tract infections. In a double-blind trial cephal-

Charing Cross Hospital, London W6 8RF

P E GOWER, MD, MRCP, consultant nephrologist

P R W TASKER, MB, BS, senior house officer, department of medicine exin and ampicillin were found to be equally effective, though cephalexin was better tolerated. ${ }^{1}$ Brumfitt and Pursell ${ }^{2}$ compared ampicillin, cephalexin, co-trimoxazole, and trimethoprim in 300 patients from three separate populations with urinary infections. The cure rate was slightly, though not significantly, higher with co-trimoxazole than with either ampicillin or cephalexin. Cure was defined at a six-week follow-up examination, and no details of the pyelograms were given.

We report a double-blind, controlled comparison of cephalexin and co-trimoxazole in a group of women with urinary infections who were fully investigated. Most were treated as outpatients.

\section{Patients and methods}

A total of 100 women with symptomatic or asymptomatic urinary tract infections were selected for study; 24 were attending a urinary infection clinic, and 76 presented in the casualty department with acute urinary symptoms. No patient had a catheter-induced infection. The diagnosis was confirmed by suprapubic aspiration of the bladder. All patients had either a blood urea or plasma creatinine estimation and an intravenous pyelogram. None were pregnant.

Tablets containing either cephalexin $(500 \mathrm{mg})$ or co-trimoxazole ( $80 \mathrm{mg}$ trimethoprim, $400 \mathrm{mg}$ sulphamethoxazole) but identical in appearance were prescribed in one-week courses of two tablets twice a day. The courses were allocated at random to successive patients in whom infection was confirmed. The patients were asked to return to the clinic to give midstream urine samples $(a)$ during treatment, (b) two weeks after completing treatment, and (c) six weeks after completing treatment. A further suprapubic aspiration of urine was undertaken if the midstream urine samples contained 